\title{
Atividades antibacteriana, antifúngica e indutora de fitoalexinas de hidrolatos de plantas medicinais
}

\section{Antibacterial, antifungal and phytoalexins induction activities of hydrolates of medicinal plants}

\author{
Gilmar Franzener ${ }^{\text {la }}$; Alexandra da Silva Martinez-Franzener ${ }^{\text {la }}$; \\ José Renato Stangarlin ${ }^{1 b^{*}} ;$ Márcio Paulo Czepak ${ }^{1 \mathrm{~b}}$; \\ Kátia Regina Freitas Schwan-Estrada ${ }^{2 *}$; Maria Eugênia Silva Cruz ${ }^{2}$
}

\begin{abstract}
Resumo
O objetivo do trabalho foi avaliar a atividade como antifúngico, antibacteriano e indutor da produção de fitoalexinas dos hidrolatos de Helietta apiculata (canela-de-veado) (HA), Conyza canadensis (buva) (CC) e Cymbopogon nardus (citronela) (CN) nas concentrações de 1, 5, 10, 15, 20 e 25\%, buscando seu uso no controle alternativo de doenças em plantas. Para o ensaio de fitoalexinas foram utilizados mesocótilos estiolados de sorgo. Para o efeito antibacteriano foi avaliado o crescimento da bactéria Xanthomonas campestris pv. campestris em meio caldo nutriente suplementado com os tratamentos, tendo como testemunha mistura de antibióticos $(22,5 \mathrm{mg} / \mathrm{L}$ de oxitetraciclina $+225 \mathrm{mg} / \mathrm{L}$ de estreptomicina). O efeito antifúngico foi avaliado através da mensuração do crescimento vegetativo, esporulação, germinação de esporos e desenvolvimento do tubo germinativo de Alternaria brassicae, sendo o fungicida azoxystrobin $(0,08 \mathrm{~g}$ i.a./L) usado como controle. Foi observado acréscimo na síntese de fitoalexinas com o aumento na concentração dos hidrolatos, sendo o melhor resultado obtido com $\mathrm{CN}, \mathrm{o}$ qual promoveu aumento de cerca de 4,3 vezes mais, seguido de HA (2,5 vezes) e CC (2,1 vezes), em relação a testemunha água. Resultados semelhantes foram obtidos para crescimento bacteriano com os seguintes resultados de inibição (em \%) no desenvolvimento da bactéria: CN: 29,8, HA: 14,9, CC: 14,6 e antibióticos: 97,7. Com relação à ação antifúngica foi observada inibição do desenvolvimento dos tubos germinativos, sendo que os hidrolatos de CC e HA inibiram 69,2 e 56,2\%, respectivamente, resultado semelhante ao fungicida. $\mathrm{O}$ hidrolato de $\mathrm{CN}$ não apresentou efeito antifúngico. Estes resultados indicam a presença de compostos indutores de fitoalexinas, antibacterianos e antifúngicos nesses hidrolatos, porém em baixas concentrações.

Palavras-chave: Antimicrobiano, Helietta apiculata, Conyza canadensi, Cymbopogon nardus, controle alternativo.
\end{abstract}

1 Mestrandos em Agronomia (a) e Professores Adjuntos (b) da Universidade Estadual do Oeste do Paraná (UNIOESTE), Centro de Ciências Agrárias, Rua Pernambuco 1777, Caixa Postal 1008, CEP 85.960-000, Marechal Cândido Rondon, PR. Tel. (45) 3284-7878.

2 Professoras Adjuntas do Departamento de Agronomia, Universidade Estadual de Maringá, Av. Colombo 5790, CEP 87.020-900, Maringá, PR.

* Bolsistas do CNPq

Autor para correspondência: José Renato Stangarlin 


\begin{abstract}
The aim of this work was to evaluate the antifungical, antibacterial and phytoalexins elicitors activities of hydrolates, for using in the alternative control of plant diseases. The hydrolates of Helietta apiculata (HA), Conyza canadensis (CC) and Cymbopogon nardus (CN) were used in the concentrations of 1, 5, $10,15,20$ and $25 \%$. In the phytoalexins assay, sorghum etiolated mesocotyls were used. The antibacterial effect was evaluated on the growth of the bacterium Xanthomonas campestris pv. campestris in liquid nutrient medium and antibiotic (oxytetraciclin $22.5 \mathrm{mg} / \mathrm{L}+$ streptomycin $225 \mathrm{mg} / \mathrm{L}$ ) was used as control treatment. The antifungical effect was evaluated on the micelial growth, esporulation, conidia germination and development of germinative tubes of Alternaria brassicae. The fungicide azoxystrobin ( $0.08 \mathrm{~g}$ a.i./ L) was used as control treatment. There was increment in the phytoalexins synthesis with the increase in hydrolates concentration. The better result was obtained with $\mathrm{CN}$ that promoted increase 4.3 times larger in relation to the value of the control treatment with water, followed by HA (2.5 times) and CC (2.1 times). Similar results were obtained to the antibacterial activity with the following inhibition results (\%) in the development of the bacterium: CN: 29.8, HA: 14.9, CC: 14.6 and antibiotic: 97.7 . The main antifungical effect was observed on the development of the germinative tubes. Hydrolates of CC and HA showed inhibition of up to 69.2 and $56.2 \%$, respectively, being similar to the fungicide azoxystrobin. The hydrolate of $\mathrm{CN}$ did not show antifungical effect. These results indicate the presence of phytoalexins elicitors, and antibacterial and antifungical compounds in those hydrolates, however in low concentrations.

Key words: Antimicrobial, Helietta apiculata, Conyza canadensis, Cymbopogon nardus, alternative control
\end{abstract}

\section{Introdução}

A utilização indiscriminada de agrotóxicos no controle de doenças de plantas tem ocasionado problemas de contaminação humana e ambiental e seleção de patógenos resistentes a esses produtos químicos (GHINI; KIMATI, 2000). Assim, práticas alternativas para o controle menos prejudiciais ao ambiente vêm obtendo cada vez mais expressão.

A diversidade de substâncias ativas em plantas medicinais tem motivado estudos na área farmacêutica, bem como o desenvolvimento de pesquisas envolvendo extratos e óleos essenciais, tendo em vista o controle de doenças em plantas, com resultados promissores.

Existem relatos da atividade direta de extratos e óleos essenciais de plantas sobre fitopatógenos como fungos, bactérias, vírus e nematóides (BALDO, 2005; FIORI et al., 2000; KAGALE et al., 2004; MOTOYAMA et al., 2003; WILSON et al., 1997), ou indireta, ativando mecanismos de defesa das plantas aos patógenos (FRANZENER et al., 2003; MOREIRA, 2003; SCHWAN-ESTRADA; STANGARLIN, 2005). Entre as respostas de defesa das plantas destacam-se as fitoalexinas, compostos antimicrobianos de baixa massa molecular sintetizados pelas plantas em resposta a ação de agentes bióticos ou abióticos, também denominados de elicitores (BONALDO et al., 2004). Mesocótilos estiolados de sorgo e cotilédones de soja são consideradas excelentes ferramentas em estudos envolvendo a ação elicitora de moléculas de origem biótica ou abiótica (CAVALCANTI; BRUNELLI; STANGARLIN, 2005).

Embora a maioria dos estudos tenha sido realizada com extratos ou óleos essenciais, outros métodos de extração ou produtos podem ser utilizados, como o hidrolato, sendo este o líquido resultante do processo de extração de óleo essencial por arraste a vapor, o qual apresenta geralmente compostos voláteis hidrossolúveis (LAVABRE, 1993) e possui grande quantidade de princípios ativos como ácidos, aldeídos e aminas. Também, hidrolatos obtidos de plantas aromáticas geralmente contêm de 0,05 a 0,20 g de óleo essencial por litro. Atualmente, os hidrolatos têm sido utilizados para preparação de xaropes e em cosmetologia (TESKE; TRENTINI, 1997). São escassas as informações do seu emprego no controle de doenças em plantas. Um dos poucos trabalhos nesse sentido relata a inibição no desenvolvimento dos fungos fitopatogênicos Botrytis alli e Sclerotium cepivorum por hidrolatos de alho (Allium sativum) e cebola (Allium cepivorum) (LOZANO et al., 2000). 
Assim, o objetivo do presente trabalho foi o de avaliar o efeito antifúngico e antibacteriano de hidrolatos sobre fitopatógenos, bem como a atividade indutora de fitoalexinas em sorgo, como indicativo de seu potencial para o controle alternativo de doenças de plantas.

\section{Material e Métodos}

Os experimentos foram realizados no Laboratório de Fitopatologia da Universidade Estadual do Oeste do Paraná - Unioeste, campus de Marechal Cândido Rondon/PR, em delineamento experimental inteiramente casualizado, com quatro repetições.

\section{Obtenção dos hidrolatos}

Os hidrolatos foram obtidos por sistema de extração de óleo essencial por arraste a vapor na Estação Experimental Antônio Carlos dos Santos Pessoa da Unioeste. Foi usada a proporção de $3 \mathrm{~kg}$ de folhas frescas para obtenção de $2 \mathrm{~L}$ de hidrolato das espécies vegetais: Helietta apiculata Benth. (canela-de-veado), Conyza canadensis (L.) Cronquist (buva) e Cymbopogon nardus (L.) Rendle (citronela). Os hidrolatos foram separados através de decantação e mantidos em garrafas plásticas (pet) envolvidas em papel alumínio e armazenados a $4{ }^{\circ} \mathrm{C}$ até o emprego nos ensaios. Imediatamente antes da utilização nos experimentos, os hidrolatos foram esterilizados através da filtragem em membrana Millipore (0,45 1/4m de diâmetro de poro). Foram avaliados os hidrolatos nas concentrações de 1, 5, $10,15,20$ e $25 \%$ obtidos pela diluição dos mesmos em água destilada esterilizada.

Produção de fitoalexinas em mesocótilos de sorgo

Sementes de sorgo [Sorghum bicolor (L.) Moench], cultivar Brandes, após desinfestadas em hipoclorito de sódio 1\% (15 min), lavadas em água destilada e embebidas em água sob temperatura ambiente por $6 \mathrm{~h}$, foram enroladas em folhas de papel de germinação umedecidas e incubadas em escuro à $28{ }^{\circ} \mathrm{C}$ durante quatro dias. As plântulas desenvolvidas foram expostas sob luz fluorescente por $4 \mathrm{~h}$ para paralisar a elongação dos mesocótilos (NICHOLSON et al., 1988).

Para determinação da produção de fitoalexinas, os mesocótilos foram excisados $0,5 \mathrm{~cm}$ acima do nó escutelar e colocados em tubos para microcentrífuga (volume de 1,5 mL) (três mesocótilos/tubo), contendo uma alíquota de 1,4 $\mathrm{mL}$ de cada concentração de hidrolato e após, mantidos em câmara úmida, a 25 ${ }^{\circ} \mathrm{C}$ sob luz fluorescente durante $60 \mathrm{~h}$. Em seguida, estes foram retirados dos tubos, secos em papel absorvente e os $5 \mathrm{~mm}$ basais de cada mesocótilo, após excisados, foram descartados. A porção superior $(2,5 \mathrm{~cm})$ após pesada e cortada em pequenos segmentos foi acondicionada em tubos para microcentrífuga contendo $1,5 \mathrm{ml}$ de metanol $80 \%$ acidificado $(0,1 \% \mathrm{HCl} ; \mathrm{v} / \mathrm{v})$ e mantida no metanol por $96 \mathrm{~h}$ na temperatura de $4{ }^{\circ} \mathrm{C}$ para extração dos pigmentos. Após determinou-se a absorbância a 480 nm (NICHOLSON et al., 1988). Como testemunhas foram empregados apenas água destilada esterilizada e o extrato aquoso (EA) da planta medicinal Artemisia camphorata (cânfora) na concentração de $10 \%$ de folhas frescas, por ser conhecido como indutor da produção de fitoalexinas em sorgo (FRANZENER, 2001), obtido em água destilada, seguido de filtragem em gaze e papel Whatman $\mathrm{N}^{\circ} 41$.

\section{Inibição do crescimento bacteriano}

$\mathrm{O}$ efeito antibacteriano foi avaliado no desenvolvimento da bactéria Xanthomonas campestris pv. campestris, isolada de folhas de repolho (Brassica oleraceae var. capitata) naturalmente infectadas e com sintomas típicos da doença conhecida por podridão negra, sendo cultivada em meio ágar nutriente. Em tubos de ensaio estéreis contendo meio de cultura caldo nutriente (5 $\mathrm{g}$ de peptona e $3 \mathrm{~g}$ de extrato de carne $/ 1000 \mathrm{~mL}$ de água destilada), foram adicionadas as concentrações dos hidrolatos e $100 \mu \mathrm{L}$ de uma suspensão bacteriana 
com $10^{8} \mathrm{UFC} / \mathrm{mL}$. Os tubos foram mantidos sob agitação durante $48 \mathrm{~h}$ a $27{ }^{\circ} \mathrm{C}$ e determinada a absorbância a $580 \mathrm{~nm}$. Nesta determinação cada tratamento teve como amostra de referência (branco) uma repetição sem a bactéria e como testemunhas apenas meio caldo nutriente sem antibiótico e outra contendo antibiótico $(22,5 \mathrm{mg} / \mathrm{L}$ de oxitetraciclina + $225 \mathrm{mg} / \mathrm{L}$ de estreptomicina).

Inibição do crescimento micelial e da esporulação

A atividade antifúngica foi avaliada no desenvolvimento de Alternaria brassicae, agente causal da mancha de alternária em brássicas que, depois de isolado, foi mantido em meio de cultivo BDA (batata-dextrose-ágar). Para realização do bioensaio de inibição do crescimento micelial os hidrolatos foram incorporados em meio de cultivo BDA semifundente $\left(60{ }^{\circ} \mathrm{C}\right)$ antes do mesmo ser vertido em placas de Petri. Uma hora após o meio ter sido vertido, um disco da cultura com $7 \mathrm{~mm}$ de diâmetro, contendo micélio de A. brassicae, foi retirado de colônias com 14 dias de idade em BDA e transferido para o centro de placas, as quais foram vedadas com filme plástico e incubadas a $25{ }^{\circ} \mathrm{C}$ durante 20 dias. $\mathrm{O}$ diâmetro das colônias (média de duas medidas diametralmente opostas) foi obtido 20 dias após incubação, momento em que as colônias fúngicas apresentaram colonização de cerca de $3 / 4$ da superfície do meio de cultura (STANGARLIN et al., 1999). As testemunhas foram constituídas pelo meio BDA com e sem o fungicida Azoxystrobin (0,08 g i.a./L).

Para determinação da esporulação, a partir de cada uma das colônias foi preparada uma suspensão de esporos através da adição de $10 \mathrm{~mL}$ de água destilada esterilizada na placa, raspagem da colônia e filtragem em gaze, e após procedeu-se a contagem do número de esporos $/ \mathrm{cm}^{2}$ com auxílio de uma câmara de Neubauer ao microscópio ótico.
Inibição da germinação de esporos

Uma alíquota de $40 \mu \mathrm{L}$ da suspensão de esporos (1 x $10^{4}$ conídios/mL) obtida de colônias de $A$. brassicae cultivadas em meio BDA por 14 dias e outra de $40 \mu \mathrm{L}$ das diferentes concentrações de hidrolato foram colocadas em cada um dos recipientes ("pocinhos") de uma placa usada em teste de ELISA (REGENTE et al., 1997). As placas foram incubadas em escuro a $25{ }^{\circ} \mathrm{C}$, e a porcentagem de germinação determinada $16 \mathrm{~h}$ após o início do experimento, através da contagem de 100 esporos por parcela ("pocinho") em microscópio ótico, tendo sido considerados germinados aqueles esporos cujos tubos germinativos apresentavam tamanho maior ou igual ao menor diâmetro do esporo. Também foram mensurados 10 tubos germinativos por parcela, para determinação do tamanho médio dos mesmos. Neste bioensaio utilizouse como testemunhas água destilada esterilizada e o fungicida Azoxystrobin (0,08 g i.a./L).

\section{Resultados e Discussão}

Produção de fitoalexinas em mesocótilos de sorgo

Os resultados do efeito de diferentes concentrações de hidrolatos na indução da síntese de fitoalexinas em mesocótilos de sorgo são apresentados na Figura 1, tendo sido observado sensível acúmulo de fitoalexinas para os três hidrolatos, principalmente nas maiores concentrações. Dentre eles, o maior efeito foi com o hidrolato de citronela, que já na concentração de $10 \%$ se destacou dos demais, promovendo, na maior concentração, incremento na síntese de fitoalexinas de até 4,3 vezes em relação à testemunha água. 


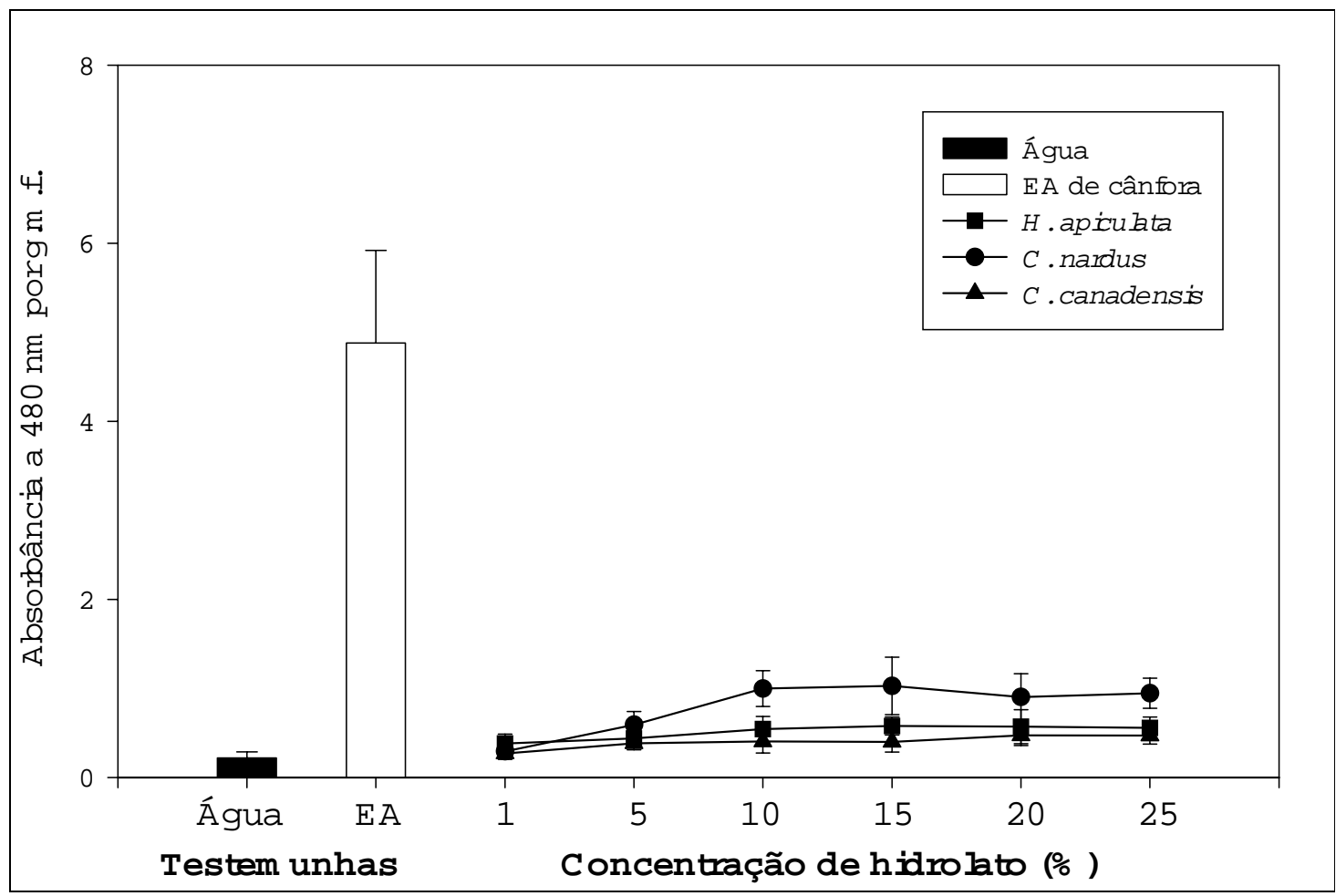

Figura 1. Produção de fitoalexinas em mesocótilos de sorgo submetidos ao tratamento com hidrolatos de plantas medicinais. As barras representam o erro padrão da média. EA= extrato aquoso de $A$. camphorata (10\%); g.m.f.= grama de massa fresca.

No entanto, esta atividade dos hidrolatos pode ser considerada baixa quando comparada ao da testemunha representada pelo extrato aquoso (EA) de Artemisia camphorata a $10 \%$ que, por sua vez, promoveu incremento de até 22 vezes em relação à testemunha água. Este comportamento do EA é pertinente com a condição de indutor da síntese de fitoalexinas relatada no trabalho de FRANZENER (2001).

Esta baixa atividade dos hidrolatos deve-se, possivelmente, à baixa concentração de compostos com propriedades de elicitores. No entanto, esta atividade não deve ser desprezada. Talvez resultados mais expressivos possam ser obtidos em ensaios in vivo, uma vez que se considera que o processo de indução de resistência em plantas não é dose dependente.

No trabalho desenvolvido por MOREIRA (2003), embora o extrato bruto aquoso de C. nardus não tenha induzido a síntese de fitoalexinas em mesocótilos de sorgo, os extratos metanólico e etanólico e frações desses extratos induziram significativamente a síntese desses compostos. Com relação a $H$. apiculata e $C$. canadensis, ainda são escassas informações de seu potencial para controle de doenças em plantas.

\section{Inibição do crescimento bacteriano}

Houve a tendência de maior inibição do crescimento bacteriano com aumento na concentração de hidrolato, destacando-se novamente o hidrolato de citronela (C. nardus) na concentração de $25 \%$, que promoveu inibição próxima a $30 \%$ em relação à testemunha água, enquanto que para os demais hidrolatos esta inibição não superou $15 \%$ (Figura 2). 


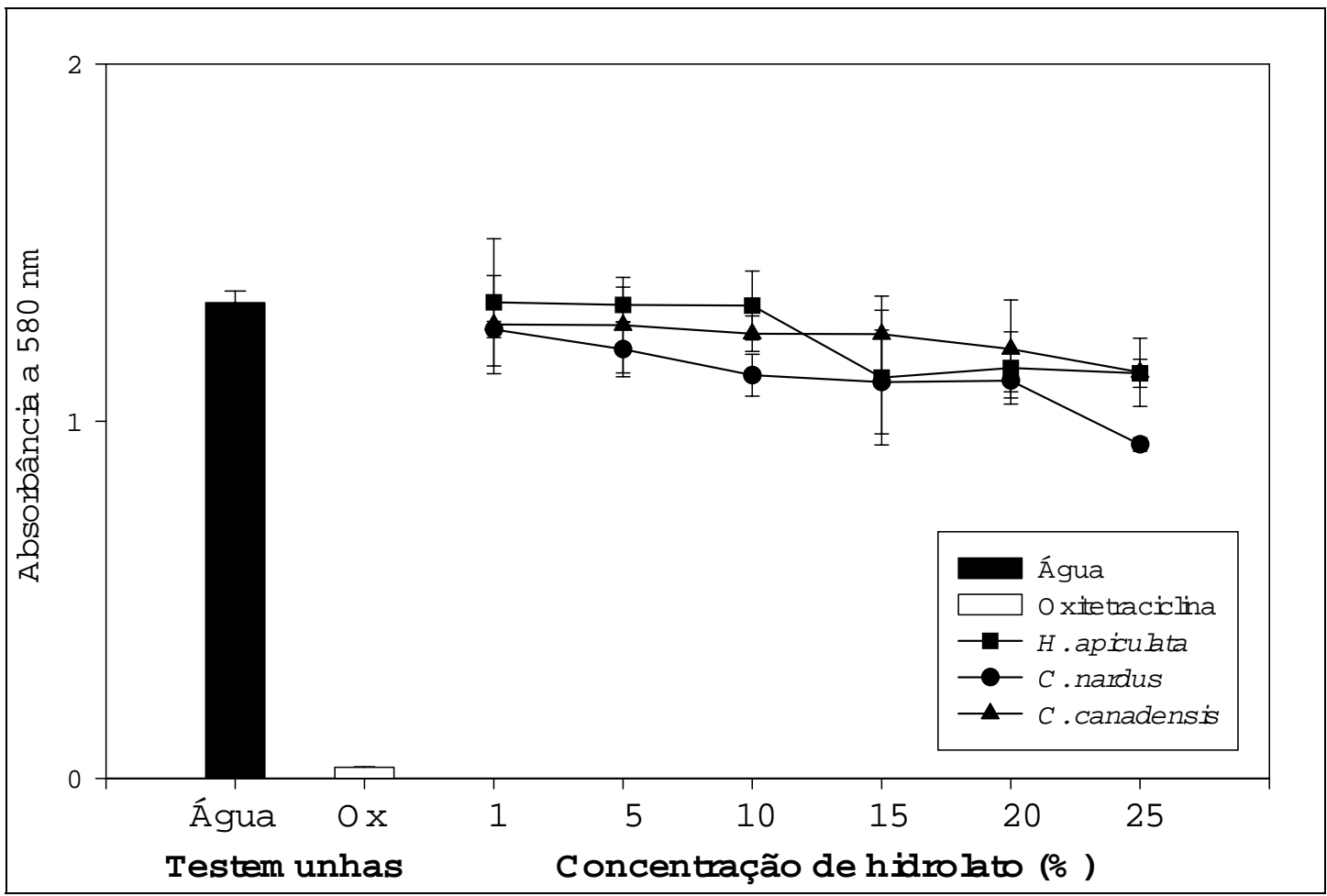

Figura 2. Crescimento de Xanthomonas campestris pv. campestris em diferentes concentrações de hidrolatos de $H$. apiculata, C. nardus e C. canadensis. As barras representam o erro padrão da média. Ox: $22,5 \mathrm{mg} / \mathrm{L}$ de oxitetraciclina $+225 \mathrm{mg} / \mathrm{L}$ de estreptomicina.

O antibiótico comercial, por sua vez, promoveu inibição de 97,7\%. Embora este efeito seja muito superior ao obtido com os hidrolatos, estes resultados indicam a presença de compostos antibacterianos nos mesmos, sobretudo no de citronela.

Apesar de serem escassos trabalhos desse tipo com hidrolatos, vários estudos relatam a atividade antibacteriana de diferentes espécies vegetais (KAGALE et al., 2004; MOTOYAMA et al., 2003; RÍOS; RECIO, 2005).

Inibição do crescimento micelial e da esporulação

O único tratamento que reduziu significativamente o diâmetro médio das colônias foi do fungicida Azoxystrobin, com inibição de 19,4\% em relação à testemunha contendo apenas meio BDA (Figura 3). Em relação aos hidrolatos, independentemente da concentração utilizada, não se observou alteração sensível no crescimento micelial.

Quanto à esporulação, o tratamento com Azoxystrobin inibiu em $84,1 \%$ a produção de esporos, enquanto que os hidrolatos de $H$. apiculata e $C$. canadensis na concentração de $25 \%$ promoveram inibições de 21 e $18,5 \%$, respectivamente. O hidrolato de $C$. nardus não inibiu significativamente a esporulação de $A$. brassicae.

\section{Inibição da germinação de esporos}

Pequena inibição da germinação foi promovida pelo fungicida Azoxystrobin e pelos hidrolatos de $C$. canadensis e $H$. apiculata na concentração de $25 \%$, que chegou a $11,2,10$ e 7,3\%, respectivamente. O hidrolato de $C$. nardus não reduziu a porcentagem de esporos germinados (Figura 4). 

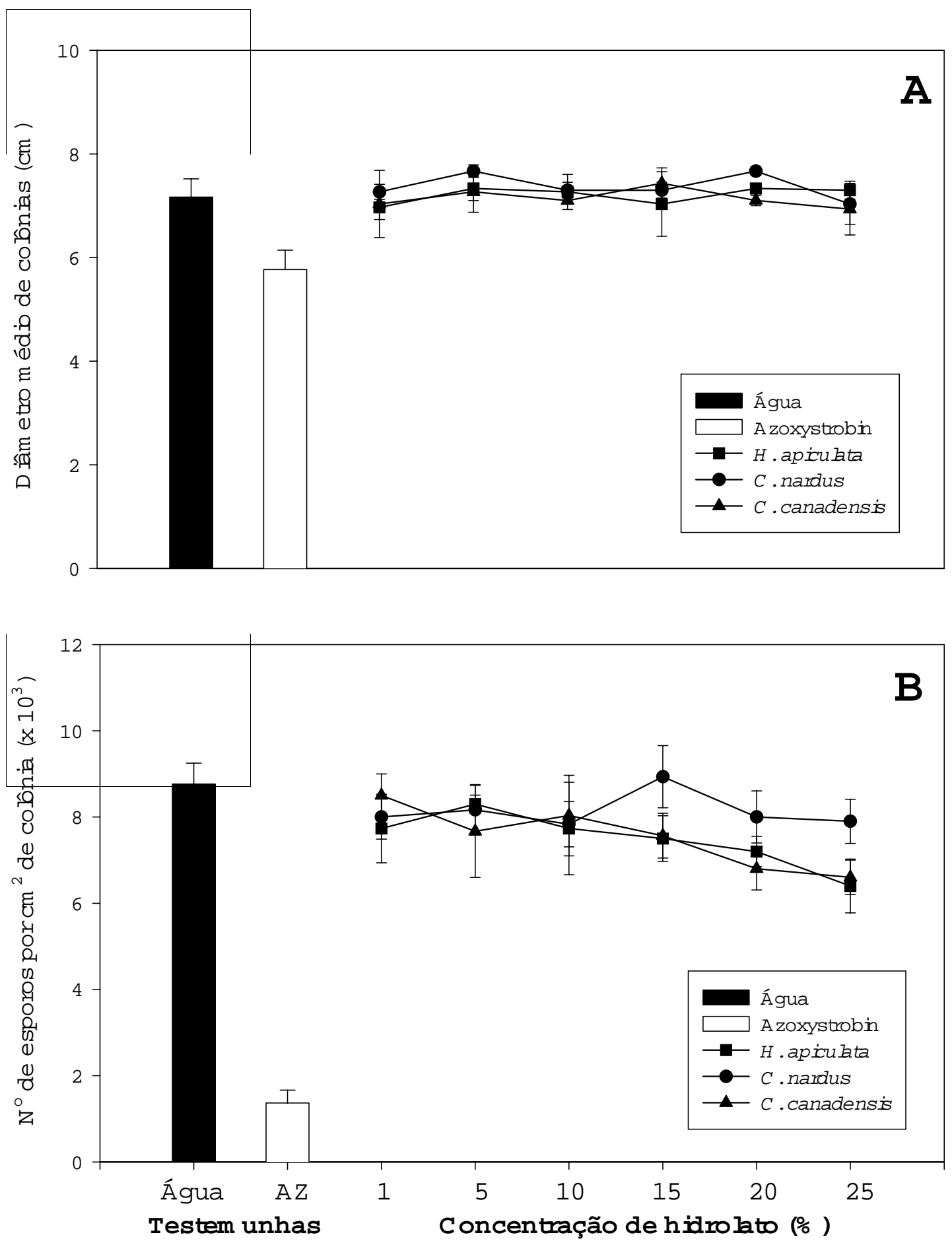

Figura 3. Crescimento micelial (A) e esporulação (B) de Alternaria brassicae em diferentes concentrações de hidrolatos de H. apiculata, C. nardus e C. canadensis. As barras representam o erro padrão da média. Az: Azoxystrobin ( 0,08 g i.a./L). 


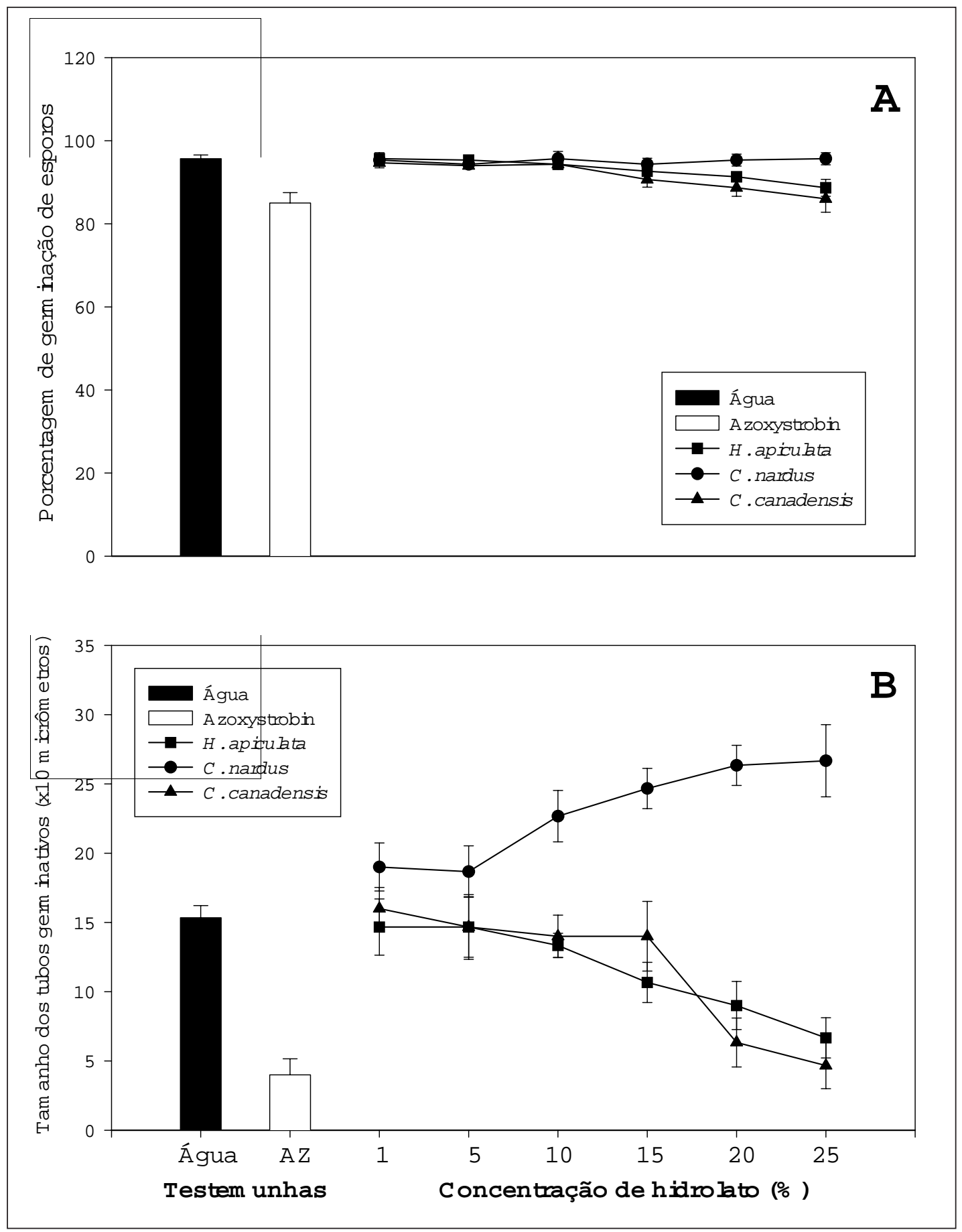

Figura 4. Porcentagem de germinação de esporos (A) e tamanho médio de tubos germinativos (B) de Alternaria brassicae em diferentes concentrações de hidrolatos de H. apiculata, C. nardus e C. canadensis. As barras representam o erro padrão da média. Az: Azoxystrobin (0,08 g i.a./L). 
Este efeito é bem mais destacado quando se observa o tamanho dos tubos germinativos. Neste caso, o fungicida Azoxystrobin e os hidrolatos de $C$. canadensis e $H$. apiculata promoveram inibição de $73,8,69,3$ e 56,2\% em relação à testemunha contendo apenas água, respectivamente. É importante ressaltar que o efeito destes hidrolatos, sobretudo o de $C$. canadensis, foi semelhante ao apresentado pelo fungicida, indicando a presença considerável de compostos antifúngicos neste hidrolatos. Talvez maior efeito ainda fosse obtido em maiores concentrações do hidrolato, pois houve a tendência de relação dosedependente, embora isso provavelmente inviabilizasse seu emprego a campo.

Quanto ao hidrolato de C. nardus, observou-se que não houve inibição, mas sim considerável estímulo ao desenvolvimento dos tubos germinativos de $A$. brassicae. Estes resultados, juntamente com os outros parâmetros avaliados sobre este fungo, evidenciam a possível ausência de compostos antifúngicos neste hidrolato, ou presença em baixas concentrações. Aliado a isso, o aumento no tamanho dos tubos germinativos (hifas) pode ser causado pela presença de outras substâncias que podem ser utilizadas como nutrientes pelo patógeno. Além disso, alguns fungos podem apresentar uma atividade de biotransformação dos compostos presentes nas plantas, o que conduziria a uma inibição do efeito fungitóxico dos mesmos (MOREIRA, 2003). Contudo, não se pode concluir se este efeito de detoxificação possa ser a causa de não haver sido observado o efeito antifúngico do hidrolato de $C$. nardus sobre $A$. brassicae.

Baldo (2005) também verificou que os extratos brutos de $C$. nardus e C. citratus promoveram estímulo na germinação de esporos de Cladosporium fulvum embora, neste caso, os extratos apresentassem efeito fungitóxico sobre o crescimento micelial e sobre a esporulação deste fungo fitopatogênico.
Também WILSON et al. (1997), utilizando extrato bruto de $C$. nardus, não obtiveram efeito antimicrobiano sobre Botrytis cinerea. Contudo, este efeito fungitóxico foi encontrado quando os autores avaliaram o óleo essencial dessa planta, em concentração de $6,25 \%$, sobre a germinação de esporos de $B$. cinerea. Desta forma, talvez compostos antifúngicos sintetizados por $C$. nardus possam se concentrar no óleo essencial e pouco estar presentes no hidrolato.

A partir dos resultados obtidos conclui-se que os hidrolatos de $H$. apiculata, C. nardus e $C$. canadensis, ainda que em baixas concentrações, possuem compostos antibacterianos, antifúngicos e elicitores de fitoalexinas.

Novas avaliações são necessárias, incluindo-se a caracterização dos compostos ativos para melhor compreensão dos mecanismos envolvidos, de maneira que os hidrolatos possam representar uma alternativa para o controle de doenças em plantas.

\section{Referências}

BALDO, M. Potencial do extrato bruto de Cymbopogon citratus (capim-limão) e Cymbopogon nardus (citronela) no controle in vitro de Cladosporium fulvum do tomateiro. 2005. Monografia (Graduação em Agronomia) Universidade Estadual do Oeste do Paraná, Marechal Cândido Rondon.

BONALDO, S. M.; SCHWAN-ESTRADA, K. R. F.; STANGARLIN, J. R.; TESSMANN, D. J.; SCAPIM, C. A. Fungitoxidade, atividade elicitora de fitoalexinas e proteção de pepino contra Colletotrichum lagenarium, pelo extrato aquoso de Eucalyptus citriodora. Fitopatologia Brasileira, Brasília, v.29, p.128-134, 2004.

CAVALCANTI, L. S.; BRUNELLI, K. R.; STANGARLIN, J. R. Aspectos bioquímicos e moleculares da resistência induzida. In: CAVALCANTI, L S.; DI PIERO, R. M. ; CIA, P.; PASCHOLATI, S. F.; RESENDE, M. L. V.; ROMEIRO, R. S. (Ed.). Indução de resistência em plantas a patógenos e insetos. Piracicaba:FEALQ, 2005. Cap.4, p.81-124.

FIORI, A. C. G.; SCHWAN-ESTRADA, K. R. F.; STANGARLIN, J. R.; VIDA, J. B.; SCAPIM, C. A.; CRUZ, M. E. S. Antifungal activity of leaf extracts and essential oils of some medicinal plants against Didymella bryoniae. Journal of Phytopathology, Berlin, v.148, p.483-487, 2000. 
FRANZENER, G. Atividade antifúngica, produção de fitoalexinas em sorgo e soja e indução de resistência em trigo a Bipolaris sorokiniana a partir da planta medicinal Artemisia camphorata (cânfora). 2001. Monografia (Graduação em Agronomia) - Universidade Estadual do Oeste do Paraná, Marechal Cândido Rondon.

FRANZENER, G.; STANGARLIN, J. R.; SCHWANESTRADA, K. R. F.; CRUZ, M. E. S. Atividade antifúngica e indução de resistência em trigo a Bipolaris sorokiniana por Artemisia camphorata. Acta Scientiarum, Maringá, v.25, p.503-507, 2003.

GHINI, R.; KIMATI, H. Resistência de fungos a fungicidas. Jaguariúna: Embrapa Meio Ambiente, 2000.

KAGALE, S.; MARIMUTHU, T.; THAYUMANAVAN, B.; NANDAKUMAR, R.; SAMIYAPPAN, R. Antimicrobial activity and induction of systemic resistance in rice by leaf extract of Datura metel against Rhizoctonia solani and Xanthomonas oryzae pv. oryzae. Physiological and Molecular Plant Pathology, Londres, v.65, p.91-100, 2004.

LAVABRE, M. Aromaterapia: a cura pelos óleos essenciais. Rio de Janeiro: Record. 1993.

LOZANO, C.; CORDOBA, N.; AVILA-DE-MORENO, C.; VELOSA, M. Evaluacion del efecto de hidrolatos de ajo (Allium sativum) y cebolla junca (Allium fistulosum) en el desarollo de los hongos fitopatogenos Botrytis alli y Sclerotium cepivorum. Fitopatologia Colombiana, Cali, v.24, p.29-32, 2000.

MOREIRA, C. G. A. Caracterização parcial de frações eliciadoras presentes em extratos de Cymbopogon nardus. 2003. Dissertação (Mestrado em Agronomia) Universidade Estadual de Maringá, Maringá.

MOTOYAMA, M. M.; SCHWAN-ESTRADA, K. R. F.; STANGARLIN, J. R.; FIORI-TUTIDA, A. C. G.; SCAPIM, C. A. Efeito antimicrobiano de extrato cítrico sobre Ralstonia solanacearum e Xanthomonas axonopodis pv. manihotis. Acta Scientiarum, Maringá, v.25, p.509-512, 2003.
NICHOLSON, R. L.; JAMIL, F. F.; SNYDER, B. A.; LUE, W. L.; HIPSKIND, J. Phytoalexin synthesis in the juvenile sorghum leaf. Physiological and Molecular Plant Pathology, v.33, p.271-278, 1988.

REGENTE, M. C.; OLIVA, C. R.; FELDMAN, M. L.; CASTAGNARO, A. P.; CANAL, L. A sunflower leaf antifungal peptide active against Sclerotinia sclerotiorum. Physiologia Plantarum, Conpenhagen, v.100, p.178-182, 1997.

RÍOS, J. L.; RECIO, M. C. Medicinal plants and antimicrobial activity. Journal of Ethnopharmacology, Kidington, v.100, p.80-84, 2005.

SCHWAN-ESTRADA, K. R. F.; STANGARLIN, J. R. Extratos e óleos essenciais de plantas medicinais na indução de resistência. In: CAVALCANTI, L S.; DI PIERO, R. M. ; CIA, P.; PASCHOLATI, S. F.; RESENDE, M. L. V.; ROMEIRO, R. S. (Ed.). Indução de resistência em plantas a patógenos e insetos. Piracicaba: FEALQ, 2005. Cap.5, p.125-138.

STANGARLIN, J. R.; SCHWAN-ESTRADA, K. R. F.; CRUZ, M. E. S.; NOZAKI, M. H. Plantas medicinais e controle alternativo de fitopatógenos. Biotecnologia Ciência \& Desenvolvimento, Brasília, n.11, p.16-21, 1999.

TESKE, M.; TRENTINI, A. M. M. Herbariu: compêndio de fitoterapia. Curitiba: Herbarium, 1997.

WILSON, C. L.; SOLAR, J. M.; EL GHAOUTH, A.; WISNIEWSKI, M. E. Rapid evaluation of plant extracts and essential oils for antifungal activity against Botrytis cinerea. Plant Disease, St. Paul, v.81, p.204-210, 1997. 